\title{
Quality of Primary Care Center Referral Letters and Feedback Reports among Sample of PHCCs in Baghdad /AI-Rusafa Health Directorate During2015
}

\author{
*Lujain Anwar Alkhazrajy ${ }^{* *}$ Wiam Kadhem Al-Muthafer
}

\begin{abstract}
Background:The referral system constitutes a key element of health system. Effective referral system between different levels of health care delivery represents a cornerstone in addressing patients' health needs.

Objectives:To assess the referral system Baghdad/ AlRusafa Health Directorate by evaluation the referral pattern and identify the quality of the referral letters and feedback reports.

Type of the study: This cross-sectional study .

Methodology : It was conducted in5PHCC in from $1^{\text {st }}$ July $2015-31^{\text {st }}$ December 2015 at Bagdad/Al-Rusafa health directorate. The study population (sampled population) included all referrals in six months. Data were entered and analyzed by using the statistical package for social science (SPSS) software version 17 for windows .

Results: The referral rate was $2.85 \%$.The variables of the referral letter (such as age, gender of the referred patient)were present, while the indication for referral(3.3\%), result of investigation done in $\mathrm{PHCC}$ $(4.67 \%)$, initial diagnosis $(5.86 \%)$, however, the name of physician and signature were not mentioned or specified in $70 \%$ of the referral letters. The rate of feedback reports received by PHCCs was $19 \%$ of total number of referrals to the hospitals. The referral rate was $(2.8 \%)$
\end{abstract}

from total number of patients seen in PHCCs. However, the quality of referral letters and feedback reports was poor in $69.5 \%$ and $78.5 \%$ respectively.

Conclusion: In this study there was a low referral percentage and low feedback report in five PHCCs of Baghdad/ Al-Rusafa health directorate compared to international literature.The quality of referral letters and feedback reports is poor and contained inadequate information and lacking important and relevant items in majority of referral needs to be improved

Key words: Referral ,Feedback report , primary health care centers(PHCCs)

\section{Al-Kindy College Medical Journal 2017: Vol. 13 No.1 Page: 1- 7}

* Consultant family physician / quality assurance \& academic performance unit/ Alkindy college of medicine/ university of Baghdad

${ }^{* *}$ M.B.CH.B / Al Rusafa Health Directorate / Ministry of Health / Iraq

Received 15 $5^{\text {th }}$ Feb 2017, accepted in final $30^{\text {th }}$ March 2017 Corresponding to : Dr Lujain Anwar Alkhazrajy , e-mail: lujainalkhazrajy@gmail.com
$\mathrm{T}$ he health services in Iraq are provided through a network of public PHC centers and hospitals where services are provided at very low charges. However, the Iraqi health system faces enormous problems that have mainly resulted from wars and economic sanctions during the last few decades. ${ }^{(1,2)}$

The Ministry of Health( $\mathrm{MOH})$ adopted a referral system in late 2008 to ensure a close relationship among all levels of the health system, to ensure people receive the best possible care closest to home, and to make cost effective use of hospitals and primary health care services. Most Primary Health Care(PHC) clinics (85\%) had a referral system record,however $(69 \%)$ did not have an electronic archive or family inventory and (64\%) said they do not have any follow up mechanisms for the patients who are in need of continuous care.$^{(3)}$ Although the MOH has established a system for patient referrals, this mechanism does not function well because of the lack of other requirements for an efficient referral system. ${ }^{(4,5)}$

Ideally, PHC centers are supposed to be the point of first contact of patients from which referral to the secondary and tertiary levels should follow a timely, smooth and organized process. ${ }^{(6,7)}$

Referrals of patients from primary care to medical specialist care, and back to primary care comprises an important activity in any healthcare system. There is evidence, that the gate-keeping role of general practitioners (GPs) increases efficacy of the system and reduces costs. ${ }^{(6,8,9)}$ Patients present to general (GPs) with undifferentiated illnesssuch that the cause of disease may be in the physical,social and or psychological domains. ${ }^{(10)}$ Different GPs select different proportions of their patients for referral to specialists. ${ }^{(11)}$ The reasons for referral may include the need to establish a diagnosis or for treatment,support and or for advice. In some cases, the reason for referral is for a routine surgical procedure in other cases the reasons for referral are more complexand may include a request for specialist input to reassure a patient that the symptoms should not cause concern. ${ }^{(12)}$ Effective referral systems between different levels of health care delivery represent a cornerstone in addressing patients' health needs efficiently. ${ }^{(13)}$

The primary function of hospital is to provide complex clinical care to patients referred from lower levels. An effective referral system requires good communication and coordination between levels of care and support from higher to lower levels to help manage patients at the lowest level of care possible... ${ }^{(14)}$

Although appropriate specialist referrals improve quality, overuse of referrals could increase use of health care services without benefit. ${ }^{(15)}$ Care provided by specialists compared with that provided by generalists is more 
costly due to the addition of expensive tests and highly selective treatments. ${ }^{(16)}$

Access to secondary care varies considerably between countries. In the United States patients can refer themselves to secondary care. But in countries like Denmark, the Netherlands, the United Kingdom, Spain, Iceland, and Norway, referrals to secondary care are largely controlled by GPs. ${ }^{(17)}$

Most countries in the Eastern Mediterranean Region (EMR) are committed to strengthening family practice, however, implementation is uneven and inconsistent. An assessment of the status of family practice revealed significant gaps in terms of political commitment, patient registration, packages of essential health services, essential medicines lists, referral systems and staff. Another big challenge is the insufficiency of trained family physicians and the inability of current training programs to meet the enormous needs. ${ }^{(18)}$

In Iraq referral system is between primary and secondary care, in practice, there is minimal coordination between the primary health care $(\mathrm{PHC})$ level and the district hospitals apart from communicable disease surveillance. The referral system is either rudimentary or practically non-existent. No system of general or family practice is yet in place. Health center and hospital care are not coordinated within district health systems. In addition, over two decades of war, conflict and prolonged economic sanctions have led to deterioration in the quality of service provision, a shortage in technical expertise and diagnostic services, and a rationing of drugs. This situation has forced patients to seek services at the tertiary care level. Consequently, the majority of people go directly to the hospital. Approximately $65 \%$ of deliveries take place at hospitals. Family planning services are also mainly provided through hospitals $(67 \%){ }^{(19)}$

The referral system given to primary care physicians is based on clear guidelines detailing the referral process. This includes the use of a pre-designed standardized referral form with important relevant clinicaland social information. ${ }^{(20)}$ The current study is part of a national project undertaken to evaluate the quality of the referral system in Iraq.

\section{Aim of the study was to :}

1-evaluatethe quality of referral letters

2-evaluate the quality of feedback reports at PHCCs in Baghdad/ Al-Rusafa Health Directorate.

\section{Subjects and Methods:}

Design:Cross-sectional study From $1^{\text {st }}$ January -31 July 2016.

Sample size: A convenient sample was chosen to represent five PHCCs at Baghdad/Al-Rusafa health directorate, these are: Bab Al-Muadham, AlMustansiriya,Al-Idrissi,Al-Dubaat ,New Suleikh PHCCs The total referral letters records during six month from $1^{\text {st }}$ July $2015-31^{\text {st }}$ December 2015 were collectedand it consist of:

- 2278 letter of referral from primary health care centers, 2012 of them were reviewed and 266 was missed

-only377 of feedback report. These numbers are obtained from the statistical form ofPHCC.

\section{Data source:}

Data were obtained from a referral form which was adapted by the Iraqi ministry of health at primary \& secondary health level, the form consists of three copies carbonated the $1^{\text {st }}$ and the $2^{\text {nd }}$ form given to the patient for receiving facility, the $3^{\text {rd }}$ form are kept in the health center for the purpose of registration and followup as if the client have the family health file kept in the file; and if it is outside the geographic area kept in the archives of the primary health center.

\section{The referral form at PHCC:}

It includes the following section:

First section: this section is about the patient and it is filled with the following information:Patient's name, Gender, Age Patient's file Number, The referred to institution and department name

\section{Second section: Referral summary}

The following information are filled in referral summary: Indication for referral, Chief complaint, Exam notes, Relevant examination finding, Current medication, Investigation, Initial Diagnosis,the name and signature of the referring physician

\section{Third section}

includes the followingcolumns:Date,Clinical findings, Tests and exams, Laboratory exams,Radiographies,Others:Finaldiag ,Management Recommendations. Name and signature of specialist.

\section{The feedback form (Hospital)}

The feedback referral information on feedback reports of clients referred out should be made on the same line of referral form as information regarding the original referralout, this facilitates follow-up.In the hospital all the results are document and recorded, then the PHCC answered by sending the first paper of the referral form via official mail.

Data Analysis:

-Descriptive statistics.In form of numbers\&percentages (graphs \& tables)

-Analytic statistics: Data of the 2012referral letters and377 of feedback report in this study were entered and analyzed by using the statistical package for social science (SPSS) software version 17 for windows.Chisquare test was used to compare the variables and the different scores of quality of referral letters in the differentPHCCs.Level of significance (P-Value) $\leq 0.05$ was considered as significant.

\section{Scoring:Scoring of referral letters:}

The important items in the referral letter were identified and assessed on the basis of the following scoring system: each one given score $(0=$ not present, $1=$ present), total score was Sixteen items demanded by the standards, with computing the median the following scores were adapted to show the quality of the referral letter:

$\leq 8=$ poor, $9-12=$ fair, $13-16=$ good

\section{-Scoring of feedback report:}

Similarly the scoring was also done for the feedback from hospitals according to the following manner: $(0=$ not available, $1=$ available). This gave a total score of eightitem with computing the median the following scores were adapted to show the quality of the feedback report: $\leq 4$ = poor, $5-6$ = fair ,7-8 = good

\section{Ethical considerations:}

The study protocol was approved by:

- The scientific committee of the Arabic council of medical specialization/ family medicine directed for Baghdad /AI-Rusafa health directorate.

-Training and Development Center Iraqi ( $\mathrm{MOH})$.

Results:

The current study showed different referral percentages from the involved PHCCs, to the secondary health care institutes the highest percentage was from New Suleikh 
PHCC (3.76\%) and Al-Mustansiriya PHCC (3.3\%) this is clearly shown in table (1).

Table (1): Distribution of percentage of referrals from PHCCs

\begin{tabular}{|l|c|c|c|}
\hline \multicolumn{1}{|c|}{ PHCC } & $\begin{array}{c}\text { No. of } \\
\text { referral }\end{array}$ & $\begin{array}{c}\text { No. of } \\
\text { patient in } \\
\text { PHCC }\end{array}$ & $\begin{array}{c}\text { Referral } \\
\%\end{array}$ \\
\hline Al- Idrissi & 434 & 20387 & $2.13 \%$ \\
\hline New Suleikh & 545 & 14489 & $3.76 \%$ \\
\hline Al-Dubaat & 206 & 10450 & $1.97 \%$ \\
\hline Mustansiriya & 660 & 19806 & $3.33 \%$ \\
\hline $\begin{array}{l}\text { Bab Al- } \\
\text { Muadham }\end{array}$ & 433 & 14768 & $2.93 \%$ \\
\hline \multicolumn{1}{|c|}{ Total } & 2278 & 79900 & $2.85 \%$ \\
\hline
\end{tabular}

The most frequently mentioned items of referral letters from PHCCS, was age (100\%), gender $(88.62 \%)$ and date of referral $(99.90 \%)$ the specialty to which the patient was referred the $(81.31 \%)$ chief complaint $(57.95 \%)$ and general examination $(89.96 \%)$, while the worst was, indication for referral (3.3\%) systemic examination (3.08\%) current medication $(0.89 \%)$ result of investigation done in PHCC (4.67\%) initial diagnosis (5.86\%). Patients file number, vital sign, Name of physician and signature were not mentioned or specified in $75 \%$ of the referral letters .

The current study showed different Frequency distribution of referrals from PHCCS to secondary health care institution the highest percentage was to Al- Kindy teaching hospital $(70.58 \%), \mathrm{Al}$ - Nu 'man General Hospital (15.61\%) and Al - Elwiyah Maternity hospital $(7.26 \%)$.Assessment of quality of referral letters reports based on the scores in different PHCCs. The quality of total referral letters was good in $(0.25 \%)$, fair in $(30.17 \%)$ and poor in $(69.58 \%)$ The majority of letters $(69.58 \%)$ were found to be of poor quality (scored 8 and less). There was a significant difference between the health centers. Al-Mustansiriya and Al- Idrissi PHCC were the worst whileNew Suleikh PHCC was the Best. Where $(30.17 \%)$ of total referral letters was fair the highest percentage (93.3\%) was from New SuleikhPHCC, while the lowest percentage was from Al Mustansiriya PHCC, (Chi-square for trend $=0.0005$, $\mathrm{p}=0.002$ ), (table 2).

The specialists to whom the patients were referred from the primary care centers to different specialties, the majority were referred to internal medicine and rheumatology (13.5\%), ophthalmology (12.9\%), orthopedics (10.4\%), ENT(9.9\%). Obstetric/gynecology and dermatology (6.9\%), while pediatrics only $(4.9 \%)$, in a few of the referrals $(1.14 \%)$ the specialty was not defined. The percentages of Physician qualification of referral physician (figure 1). The highest percentage for unclassified (signature only) $64 \%$, while specialist (18\%), and general practice $(10 \%)$, in a few of the referrals $(0.1 \%)$ the qualification of referral physician was not defined. The most frequently mentioned items of feedback reports were Date of feedback(73.6\%), diagnosis(62.9\%)andManage ment:(The necessary was made) $46.9 \%$, Name \& sign of specialist andName of the Hospitalmentioned in only (40\%).Other important items such as investigation (14.7\%), Medication (7.5\%), Clinical finding, Referral to, Revisit Date and Admission were mentioned in less than $(4 \%)$ of the reports.

\section{Table (2): Quality of referral letters inPHCCs}

\begin{tabular}{|c|c|c|c|c|}
\hline phcc & Poor & Fair & Good & Total \\
\hline Idrissi & $\begin{array}{c}422 \\
(97.2 \%)\end{array}$ & $\begin{array}{c}12 \\
(2.8 \%)\end{array}$ & $\begin{array}{c}0 \\
(0 \%)\end{array}$ & 434 \\
\hline Suleikh & $\begin{array}{c}22 \\
(6.7 \%)\end{array}$ & $\begin{array}{c}308 \\
(93.3 \%)\end{array}$ & $\begin{array}{c}0 \\
(0 \%)\end{array}$ & 330 \\
\hline Dubaat & $\begin{array}{c}119 \\
(63.6 \%)\end{array}$ & $\begin{array}{c}67 \\
(35.8 \%)\end{array}$ & $\begin{array}{c}1 \\
(0.5 \%)\end{array}$ & 187 \\
\hline $\begin{array}{l}\text { Mustan } \\
\text { siriya }\end{array}$ & $\begin{array}{c}660 \\
(100 \%)\end{array}$ & $\begin{array}{c}0 \\
(0 \%) \\
\end{array}$ & $\begin{array}{c}0 \\
(0 \%)\end{array}$ & 660 \\
\hline $\begin{array}{l}\text { Bab Al- } \\
\text { Muadh } \\
\text { am }\end{array}$ & $\begin{array}{c}177 \\
(44.1 \%)\end{array}$ & $\begin{array}{c}220 \\
(54.9 \%)\end{array}$ & $\begin{array}{c}4 \\
(1.0 \%)\end{array}$ & 401 \\
\hline Total & $1400(69.58)$ & $\begin{array}{c}607(30.1 \\
7)\end{array}$ & $5(0.25)$ & 2012 \\
\hline & & $=0.002$ * & & \\
\hline
\end{tabular}

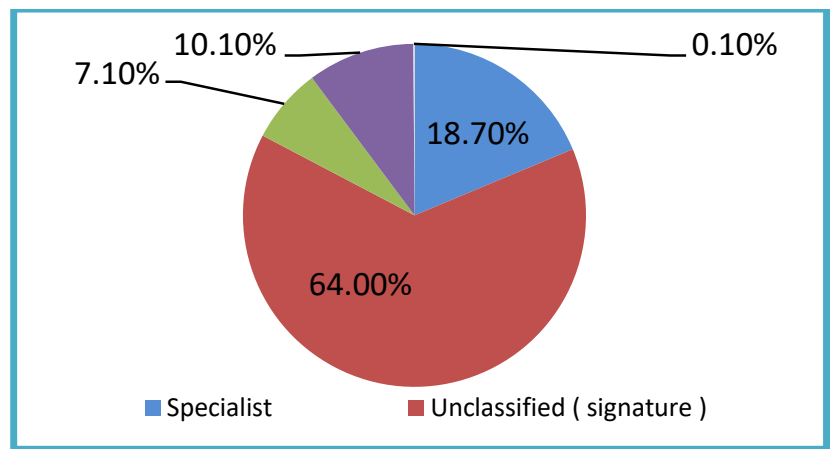

Fig (1): distribution of the referral letters by qualification of referral physician

The most frequently mentioned items of feedback reports were Date of feedback(73.6\%), diagnosis(62.9\%)andManagement:(The necessary was made) $46.9 \%$, Name \& sign of specialist andName of the Hospitalmentioned in only (40\%).Other important items such as investigation (14.7\%), Medication (7.5\%), Clinical finding, Referral to, Revisit Date and Admission were mentioned in less than (4\%) of the reports. The total feedback reports percentages to PHCC (16.5\%) [85.15\% from Al-Nu 'man General Hospital and14.85\% from AL - Elwiyah Maternity hospital].There was a significant difference between the health centers. The highest feedback percentage was from New Suleikh PHCC (58.89\%), while Al-Dubaat PHCC does not have any feedback reports .

Assessment the quality of referral feedback reports based on the scores in different PHCCS. The vast majority of feedback reports $(78.51 \%)$ were found to be of poor quality 
.Al- Idrissi, Al -Mustansiriya and Bab Al- Muadham PHCCs got total percentage $(100 \%)$ of poor quality. While less (than $1 \%$ ) good quality (scored $7-8$ ) and $(24.9 \%)$ of fair quality, that's for New Suleikh PHCC $(p=0.0000)$, (table 3). Table (3): Quality of feedback reports to PHCCs

\begin{tabular}{|c|c|c|c|c|}
\hline \multirow{2}{*}{ PHCC } & \multicolumn{4}{|c|}{ Quality of feedbackNo. (377) } \\
\hline & Poor & Fair & good & Total \\
\hline Al- Idrissi & $\begin{array}{c}9 \\
(100 \%)\end{array}$ & 0 & 0 & 9 \\
\hline $\begin{array}{l}\text { New } \\
\text { Suleikh }\end{array}$ & $\begin{array}{c}240 \\
(74.8 \%)\end{array}$ & $\begin{array}{c}80 \\
(24.9 \%)\end{array}$ & $\begin{array}{c}1 \\
(0.3 \%)\end{array}$ & 321 \\
\hline $\begin{array}{l}\text { Mustansiriy } \\
\text { a }\end{array}$ & $\begin{array}{c}42 \\
(100 \%)\end{array}$ & 0 & 0 & 42 \\
\hline $\begin{array}{l}\text { Bab Al- } \\
\text { Muadham }\end{array}$ & $\begin{array}{c}5 \\
(100 \%)\end{array}$ & 0 & 0 & 5 \\
\hline Total & $\begin{array}{c}296 \\
(78.51 \% \\
)\end{array}$ & $\begin{array}{c}80 \\
(21.22 \% \\
)\end{array}$ & $\begin{array}{c}1 \\
(0.26 \%)\end{array}$ & 377 \\
\hline \multicolumn{5}{|c|}{$P$-value $=0.0001^{*}$} \\
\hline
\end{tabular}

The percentages by Physician qualification for feedback report shown in figure (3). The highest percentage (50\%) for unclassified (signature only), while specialist (37\%), and Resident permanent $(5.8 \%)$, in a few of the letter (5.9\%) the Physician qualification of feedback report was not defined.

Discussion:

The referral system constitutes a key element of health system. Effective referral system between different levels of health care delivery represents a cornerstone in addressing patients' health needs.

Percentages of the Referral letter andfeedback: In this study, we found that the overall referral percentage observed was $2.8 \%$ from total number of patients seen in PHCCs. Which was similar to the results obtained in study don in Taif governorate, Saudi Arabia 2015, were the referral rate was $(2.7 \%.) .{ }^{(21)}$ On the other hand the referral rate of the current study was lower than those obtained in a study done inDuhok, Iraq 2014, and also in Erbil, Iraq 2012. (15.4\%, $6.0 \%$ respectively). ${ }^{\left(22,{ }^{23)}\right.}$ This suggests that low referrers and high referrers are able to generate equivalent outcomes - perhaps because differences in referral behavior are balanced against differences in other aspects of clinical behavior, however, higher referral rates were associated with higher patient satisfaction. ${ }^{(24)}$ differences can be attributed to environmental factors, geographical location, and socioeconomic variations, yielding new clues about the referral system. ${ }^{(25)}$ This might be the result of the difference in health system compared with the other studies, or perhaps the time difference between our study and other studies.

Regarding feedback in this study, we found low percentage $(16.5 \%)$ of hospital feedback reports, These results are higher than those found in a study done in Egypt, 2015 were only 13\% of referred patients returned back with feedback reports, ${ }^{(26)}$ poor feedback rate of $5.4 \%$ also was shown in a study done in South Africa $2015 .{ }^{(27)}$ On the other hand there was higher percentages of feedback reports in Asir region, Saudi Arabia,were hospitals sent feedback reports for only (22$39 \%),{ }^{(28)}$ comparing with higher rates in some western countries (55-88\%). ${ }^{(29)}$

Approximately most of the hospital feedback reports (85.15\%) were received from the AL- Nu 'man General Hospital, while the rest (14.85\%) were received from the $\mathrm{Al}$ - Elwiyah Maternity hospital, the high rate answers to referral letters from the $\mathrm{Al}-\mathrm{Nu}$ 'man General Hospital may be related to influence of the method of communication, by electronic feedback on answers. The reason for such a low rate of feedback reports, somemight be pertained to the work situation at the hospital, could be the lack of awareness on the part of hospital consultants of the importance of communication with PHCCsin maintaining the continuity of care and patient satisfaction. Others to the doctors' perceptions of their role in the healthcare system, to factors concerning the referral itself, and to doctors' impression that it is futile to write replies and that there is no benefit for them to do so.However, as long as the reasons for not replying are not specifically identified and addressed, personnel at PHC services will remain frustrated by the silence from secondary and tertiary levels of care.

\section{Frequency distribution of Components of referral letter and feedback report:}

The referral letters in this study contained inadequate information. Those related to name of physician and signature were not mentioned or specified in $(70 \%)$ of the referral letters. This assessment agreed with Duhok study, Iraq (2014), were the name of the referring doctor was absent/unclear on $72.4 \%$ of referral notes, ${ }^{(22)}$ and inconsistent to a study done in Qassim region (2007), were the name of physician and signature doctor was absent/unclear on $20 \%) .{ }^{(30)}$ The current study showed that the important and relevant items such as chief complain was filed in $(57.95 \%)$ of referrals; which is near the study done in Ethiopia,2010 [chief complaint of patients were documented in61.9\%]. (31) And inconsistent with the result of study done in Sri Lanka,2013 [chief complaint of patients were documented in $91 \%$ of the letters, respectively]. ${ }^{(32)}$ Vital sign and Patients file number was filed in $23 \%$ and $21 \%$ of referral; which is near the study done in Addis Ababa, Ethiopia ,2014 [the vital signs $15.3 \%$ ]. ${ }^{33)}$ And significantly lower than studies done in Qassim region, Saudi Arabia [vital sign $70.3 \%$, Patients file number $92.1 \%$ ]. ${ }^{(30)}$ Result of investigation done in PHCCs was filed in $4.6 \%$ of referral which is significantly lower than studies done in UK,and inSri Lanka(2013); [Investigation for the current condition was mentioned in $73.7 \% 21.9 \%$ of the letters, respectively]. ${ }^{(34,32)}$

Initial diagnosis was not mentioned in $94 \%$ of referral letters this assessment inconsistent with studies done inUAE, Nigeria[Diagnosis was not mentioned in $22.8 \%, 38.6 \%$ respectively]. ${ }^{(35,36)}$ Current medication mentioned in less than $1 \%$ of referrals, which is much lower than study done in Australian and in Qassim region $\left(60 \%, 52.5 \%\right.$, respectively). ${ }^{(37,30)}$ While important and relevant items such as indication for referral specified in $(3.3 \%)$ of referrals which is lower than study done in Duhok ,Iraq, were indication for referral provided 
in $22.4 \%$ of referral notes. ${ }^{(22)}$ And two studies done in Qassim region, and in South eastern Saudi Arabia were the indication for referral specified in $[90 \%, 85.6 \%$ respectively]. ${ }^{(30,38)}$

This study showed that the majority of patients were referred for further management. Despite this, the final diagnosis was specified in $(62 \%)$ of feedback reports; This assessment was near those obtained in South Africa and in Southeastern Saudi Arabia (58.6, 66.7\% respectively) ${ }^{(27,38)}$ While less than the result reported by study done in Qassim region ,were diagnosis present in $(77.9 \%)$ of feedback reports. ${ }^{(30)}$ In this study the investigations done at the hospitals were only recorded in $(14 \%)$ of the feedback letters, and clinical finding recorded in only (4\%) which were near those obtained in Asir region, Saudi Arabia,were the result obtained $\left(21.5 \%, 5.9 \%\right.$ of feedback reports, respectively), ${ }^{(28)}$

In $85 \%$ of the feedback reports there were no clear recommendations from the specialists. This is similar to the result obtained in Asir region, Saudi Arabia, were no clear recommendations in $(90 \%) .{ }^{(28)}$ While it was less than the results reported in Qassim region, were [no clear recommendations reported in $34 \%,{ }^{(30)}$

In this study, we found that name\& signiture of specialist recorded in (40\%)feedback reports which similar to the result reported in Qassim region,were recorded in $(41.8 \%),{ }^{(30)}$ and lower than those obtained in Southeastern Saudi Arabia, and study done in South Africa, were name \& sign of specialist recorded in $89.2 \%, 60.8 \%$ of feedback reports respectively]. ${ }^{(38,27)}$ In this study we found $53 \%$ mention the plan of management; only $7 \%$ record the treatment while the remaining $46 \%$ mention (It has been making the necessary). Which is lower than the result done in South Africa, [where treatment recommendations recorded in63\%]. ${ }^{(27)}$

The reasons behind skipping the referral feedback notes might be related to either the doctors were overloaded or they thought it was of no use, and some did not re-send the patient to the PHCCs at all.

\section{Distribution of referral letters by specialist:}

The current study showed that the majority were referred to departments of both internal medicine and rheumatology, ophthalmology, this result simillar to a study done in Iran in this study Internal Medicine had received $(16 \%)$ of the referred patients. ${ }^{(39)}$ While it differs from the studies done in Erbil, Iraq, in Qassim region, in Egypt were the most frequent being pediatric $27 \%$, dermatology $25.5 \%, \quad$ ophthalmology
respectively].

In some cases, physicians referreon paitient demandwhich is wrong pracice, also personal knowledge of the specialist was the important reason for selecting a specific specialist in addition the referral decisions are influenced by a complex mix of patient, physician, and health care system structural characteristics. Factors associated with more discretionary referrals may lower thresholds for referring problems that could have been managed in their entirety within primary care settings. ${ }^{(40)}$

\section{Quality of referral letter and feedback reports :}

The quality of the referral letters and feedback reports reflect the communication between the primary care physicians and specialists in hospitals. The assessment of quality of referral letters inthis study was poor, this result similar to a study done in Duhok health district which found that more than half of referrals being inappropriate. ${ }^{(45)}$ Inconsistent results to this study regarding quality of referral wasreported in Qassim region [the poor quality recorded in $17.6 \%$ ]. ${ }^{(30)}$ In Asir region,Saudi Arabia and in Southeastern Saudi Arabia [The study showed that the inappropriate quality of referral letter $42.4 \%$ and $12 \%$ respectively, inappropriate if it scored $<70 \%$ ]. ${ }^{(38,62)}$ The present study highlights several shortcomings in the referral process, lack of physician knowledge of referral completion could lead to overuse quality problems, resulting from inadvertent duplication of tests, procedures, or prescribing of medications, also Iso these variations in results may be the result of differences in knowledge, attitudes, and practices as well as working in a site having good referral system.

Regarding feedback letters the current study were with poor quality, but it differs from study reported in Southeastern Saudi Arabia ( The study showed that the inappropriate quality of specialists feedback $(53 \%)),{ }^{(38)}$ in Qassim region study reported poor quality in $29.7 \%$ of feedback reports]. ${ }^{(54)}$ The possible reasons for the poor quality of feedback reports were unclear handwriting, lack of appropriate means of communication between primary health care centers and hospitals, and lack of resources. The referral process is a critical component of quality clinical care, optimal communication involves transfer of relevant clinical information, and Breakdowns in this communication can lead to poor continuity of care, delayed diagnoses, polypharmacy, increased litigation risk, and unnecessary testing. ${ }^{(39)}$

\section{Conclusions:}

The overall referral percentage observed and feedback report was low in Baghdad/ Al-Rusafa health directorate. The referral letters and feedback reports that were examined in this study contained inadequate information and lack of important and relevant items. The quality of referral based on quality of referral letters and feedback reports was poor and needs to be improved.

\section{References :}

1.World Health Organization (WHO). Iraq Health System Profile. Cairo: EMRO,2006. Available from: http://apps.who.int/medicinedocs/documents/s17295e/s 17295e.pdf

Ali MM, Shah IH. Sanctions and childhood mortality in Iraq. Lancet 2000; 355:1851-7.

3.U.S. Agency for International Development (USAID) under Primary Health Care Project in Iraq (PHCPI).Baseline assessment report. 2011;Available from: http://pdf.usaid.gov/pdf docs/PA00J3BP.pdf 4.Alwan A. Health in Iraq: The current situation, our vision for the future and areas of work. 2nd ed. Baghdad: Ministry of Health, 2004.

5.World Health Organization (WHO). Country Cooperation Strategy for WHO and Iraq 2012-2017. Cairo: EMRO; Available from: 
http://www.who.int/countryfocus/

cooperation strategy/ccs irq en.pdf.

6.Kvamme OJ, Olesen F, Samuelson M. Improving the interface between primary and secondary care: a statement from the European Working Party on Quality in Family Practice (EQuiP). Qual Health Care. 2001: 10:33-9.

7.Grumbach K, Selby JV, Damberg C, Bindman AB, Quesenberry CJ, Truman A, et al. Resolving the gatekeeper conundrum: what patients value in primary care and referrals to specialists. JAMA 1999: 282:261-6. 8.Avorn J, Bohn RL, Levy E, Levin R, Owen WF JR, Winkelmayer WC, Glynn RJ. Nephrologist care and mortality in patients with chronic renal insufficiency. Arch Intern Med. 2002; 162: 2002-2006.

9.Frieri M, Therattil J, Dellavecchia D, Rockitter S, Pettit $\mathrm{J}$, Zitt M. A preliminary retrospective treatment and pharmacoeconomic analysis of asthma care provided by allergists, immunologists, and primary care physicians in a teaching hospital. J Asthma. 2002; 39: 405-412.

10.Phillips WR and Haynes DG. The domain of family practice: scope, role, and function. Family Medicine. 2001;33(4):273-7.

11.Donnell CA. Variation in GP referral rates: what can we learn from the literature? Family Practice. 2000;17(6):462-71.

ration strategy/ccs irq en.pdf

12. Hamilton W. Cancer diagnosis in primary care. British Journal of General Practice. 2010;60(571):121-8.

13.Rosemann T, Wensing M, Rueter G, Szecsenyi J. Referrals from general practice to consultants in Germany: If the GP is the initiator, patients' experiences are more positive. BMC Health Serv Res 2006: 6:5.

14. Hensher M., Price M., Adomakoh S. Referral Hospitals, in Disease Control Priorities in Developing Countries. In: A Copublication of Oxford University Press and The World Bank, Jamison DT,Breman JG, Measham AR, Alleyne G, Claeson M, et al. (Eds.), 2006. ISBN-10: 0-8213-0821361791, pp: 1229-1243.

15.Donohoe MT. Comparing generalist and specialty care: discrepancies, deficiencies, and excesses. Arch Intern Med. 1998;158(15):1596-1608

16. Guevara JP, Hsu D, Forrest CB. Performance measures of the specialty referral process: A systematic review of the literature. BMC Health Services Res. 2011;11: 168.

17.Ringberg U, Fleten N, DeraasTS, HasvoldT, Førde O. High referral rates to secondary care by general practitioners in Norway are associated with GPs' gender and specialist qualifications in family medicine, a study of 4350 consultations. BMC Health Services Research. 2013; $13: 147$.

18.World Health Organization(WHO). The work of WHO in the Eastern Mediterranean Region: annual report of the Regional Director 2014.Available from: http://applications.emro.who.int/docs/RD Annual Rep 201516491 EN.pdf

19.World Health Organization (WHO) .Basic Health Service Package for Iraq (BHSP)., Ministry of Health $(\mathrm{MOH})$ January2009. Available from: http://applications.emro.who.int/dsaf/libcat/EMROPD200 9 109.pdf

20.U.S. Agency for International Development (USAID) under Primary Health Care Project in Iraq (PHCPI). Referral System Revised guideline, Ministry of Health $(\mathrm{MOH})$ in March 22, 2012 Contract AID-267-C-11-
00004.Availablefrom:

http://pdf.usaid.gov/pdf docs/PA00KCB7.pdf

21.AlGhamdi OM, AL-Malki BM, Nahhas AE, AL-Malki $A D$. Rate of referral from primary health care to secondary health care among governmental hospitals in Taif governorate, KSA. International Journal of Medical Science and Public Health. 2015; 4(10): 1457-63.

22. Younis S, Al-Dabbagh S, Habeeb A, Aswad S, Mulder J, SanaanR,et al. Or809 Patient Referrals From Primary Health Care Center To Hospitals In The Duhok Health District: $50 \%$ Unnecessary, Kurdistan Region of Iraq. Wonca 2014.

23.Shabila NP, Al-Tawil NG, Wahab MA, Al-Hadithi TS, Sondorp E. Assessment of the Iraqi primary care referral system: reporting a high self requested referral rate. Middle East Journal of Family Medicine. 2012; 10(3): 410. $7 p$.

24.Franks $\mathrm{P}$, Mooney $\mathrm{C}$, Sorbero $\mathrm{M}$. 'Physician referral rates: style without much substance?' Med Care. 2000;38(8):836-46.

25.Jani A, Jenner L, Ma F, Dutton S, Stevens R, Sharma RA. Referral performs improve compliance to national colorectal two-week: does this impaction affect cancer detection rates? Colorectal Dis. 2012; 14(11):1351-56.

26.FarahatT, Al-Kot M, Aldemerdash M. Current situation of the referral system in family practice in Shebein El-Koum District, Menoufia Governorate, Egypt. Menoufia Medical Journal. 2015;28:360-66.

27.Legodia TL, Wolvaardta JE. A blank page: feedback from first referral hospitals to primary health care clinics. South African Family Practice. 2015;57(4):282-85.

28. Khattab MS, Abolfotouh MA, Al-Khadi YM, Khan MY. Studying the referral system in one family practice center in Saudi Arabia. Ann of Saudi Med. 1999;19(2):167-70.

29.Jarallah JS. The quality of referral letters in two health centers in Riyadh. Ann Saudi Med .1991;11(6):658-62.

30.Al-Alfi MA, Al-Saigul AM, Abed-Elbast AM, Sourour AM, Hasnin A Ramzy HA. Quality of primary care referral letters and feedback reports in buraidah, Qassim region, Saudi Arabia. J Family Community Med. 2007;14(3): 113-7.

31.Abate B, Enqueselassie F. Information use in patients referred at TikurAnbessa specialized hospital, Addis Ababa. Ethiopia. Ethiop Med J. 2010;48(2):12335.

32.Ramanayake RPJC, Perera DP, De Silva AHW, Sumanasekera RDN, Jayasinghe LR, Fernando KAT, et al. Referral letters from general practitioner to hospitals in Sri Lanka; Lack information and clarity. Middle East Journal Of Family Medicine. 2013; 11(9): 14-20.

33.Mulunesh, Taye. Assessment of completeness of documentation of referral papers and reasons for referral among referred patients to TASH ED. Diss. AAU, 2014. 34.Ukachukwu V, Alam A, Baskar S, Price T, Venkatachalam S. 70. How Adequate are Rheumatology Referral Letters? A Prospective Review of Referrals to A Secondary Care Rheumatology Service. Rheumatology. 2014; 53(suppl 1), i81-i82.

35.Moselhy HF, Salem MO. Referrals to Psychiatric Service in United Arab Emirates: An Analysis of the Content of Referral Letters International Journal of Health Sciences, Qassim. 2009; 3(1):13-8.

36. Orimadegun AE1, Akinbami FO, Akinsola AK, Okereke JO. Contents of referral letters to the children emergency unit of a teaching hospital, southwest of 
Nigeria. PediatricEmerg Care. 2008; 24(3):153-6. doi:10.1097/PEC.0b013e3181666f9c

37.Ong SP, Lim LT, Barnsley L, Read R. General practitioners' referral letters--Do they meet the expectations of gastroenterologists and rheumatologists?. Australian family physician. 2006: 35(11); 920.

38.Abdelwahid HA, Al-Shahrani SI, Elsaba MS, Elmorshedi WS. Patterns of referral in the Family
Medicine Department in Southeastern Saudi Arabia. Saudi Medical Journal. 2010;31(8):925-30 .

39.Chaman R, Amiri M, Raei DM. The national family physician and the quality of referral system. payeshjournaliran. 2012:11(6);785-90.

40.Forrest CB, Nutting $P$, Star field B, von Schrader S. Family physicians' referral decisions : results from the ASPN referral study. J Fam Pract. 2002 ; 51:215-22. 